\title{
Numerical Simulation of Tidal Flow and Suspended Sediment Concentration Field in a Marina Project
}

\author{
RuiJin Zhang ${ }^{1,2, a}$, JinMei Zhou ${ }^{1}$, XueZhi Huang ${ }^{1} \&$ Yan Zhang ${ }^{1}$ \\ ${ }^{1}$ College of Marine Technology and Environment, Dalian Ocean Univ., Dalian 116023, China \\ ${ }^{2}$ Key Laboratory of Nearshore Marine Environmental Research, Dalian 116023, China \\ aruijinz@dlou.edu.cn
}

Keywords: tidal current; sediment; numerical modeling

Abstract: It is an effective way for reclamation to expand our living space and improve our living environment, but with the reclamation construction more and more, it makes land and sea environments tremendous influence and destruction in recent years. In this paper, by using the numerical simulation methods, analyze the change of tidal current field after reclamation. During construction, utilizing MIKE21 software suspended sediment concentration field mathematical model to analyze the construction of suspended sediment concentration distribution, and then to study the impact on the surrounding waters reclamation suspended sediment. It concluded: This project will result of the marine environment to some extent in the construction, but this effect is temporary, after the construction, suspended sediment concentrations in the sedimentation gradually reduced pollution will disappear.

\section{Introduction}

In today's society ,it is important of reclamation to expand and improve human living space. Each year more factories will establish and develop on the land which we will obtain more by reclamation. At the same time, reclamation will bring great harm to our survival environment. Reclamation projects may change the shoreline, hydrodynamic field around to produce certain effect, and in the construction period caused by excavation, such as dredging and reclamation technology of suspended sediment pollution of the waters around it. So we should research the change of hydrodynamic field, suspended sediment field before and after making reclamation projects. Due to the rapid development of numerical simulation technology, more and more scholars began to study the effects of reclamation engineering on the surrounding environment by using the method of numerical simulation.

Foreign numerical model started earlier than the domestic, the mature commercial software and open source model is relatively more. Domestic research in this field is also very much, at the same time, some monographs about sediment mathematical modeling also come out. But because of sediment issues outstanding, complex problem, there is no mature commercial software and the advent of the world-famous open-source model. From development of sediment numerical models, the following aspects to point: from the dimensions of the research, has experienced from one dimension to the process of simple one-dimensional to two-dimensional and then three-dimensional. The one-dimensional mathematical model of the suspended sediment of Qiantang River is established by Bingnan Lin, analysis the relationship between sediment deposition velocity and sediment concentration and average half tide sediment-carrying capacity. One-dimensional ignores the estuarine sediment numerical simulation of many influence factors, and can't reflect the overall sediment transport process, therefore, with further research, two-dimensional sediment numerical simulation gradually replaced the one-dimensional sediment numerical simulation. Guangqian Wang and Jianjun Zhou combined with the equations of motion and sediment movement mechanism, deduced the two-dimensional sediment density current movement equation, flume experiment, the analog computation result comparing with test results, the applicability of the results to verify the mathematical model. Van Rijn in the study based on the analysis of the basic physical parameters, established of a three-dimensional mathematical model for sediment transport a slowly varying flow 
through a flat two-dimensional model and a logarithmic velocity profile to achieve the current field of simulation.

\section{Numerical simulation of tidal current field}

According to the engineering layout, the current field after the completion of the project is predicted. Figure 1-4 respectively for the high tide and ebb tide intermediate time flow field pattern before and after the project. By comparing tidal current field before and after project construction can be seen that, before and after completion of the velocity and flow have different degrees of change.

To further understand the impact on the nearby waters of tidal current field after this project completed, in the waters near the periphery of the project selected seven representative points, \#1 -\#3 from distance of engineering is about $500 \mathrm{~m}$, \#4 to \#7 from distance of engineering is about $1000 \mathrm{~m}$. By comparing results and the predicted results before and after construction of the trend calculation representative points, indicating that the project near the sea change current field. The relative position of the representative point is as shown in figure 5.

At high tide, the representative point increase in the flow rate, the range of variation of $0.1 \sim 0.3$ $\mathrm{cm} / \mathrm{s}$, the flow change is tiny, the maximum relative change of \# 1 is $11.49 \%$. At ebb tide, most of the point velocity decreases, ranged from $0.8 \sim-1.5 \mathrm{~cm} / \mathrm{s}$ (worth to increase, negative to reduce), the flow change is tiny, the maximum relative change of \# 2 is $8.26 \%$. The influence of engineering construction on the ebb is more obvious.

View of the distance from engineering point, the farther distance from project of the representative point, the smaller velocity relative changes (worth to increase, negative to reduce). $500 \mathrm{~m}$ from project \#1, \#2, \#3 current speed variation range of $40.54 \%$ to $40.54 \%$, current direction change 11.49\% - 11.49\%;1000 m from project \#4 , \#5 , \#6 , \#7 current speed variation range of 12.12\% 8.11\%, current direction change 3.55\% - 0.05\%, which less affected.

In summary, when the project completed, the change of velocity from the engineering $1000 \mathrm{~m}$ at less than $1.5 \mathrm{~cm} / \mathrm{s}$, the relative variation of less than $13 \%$.

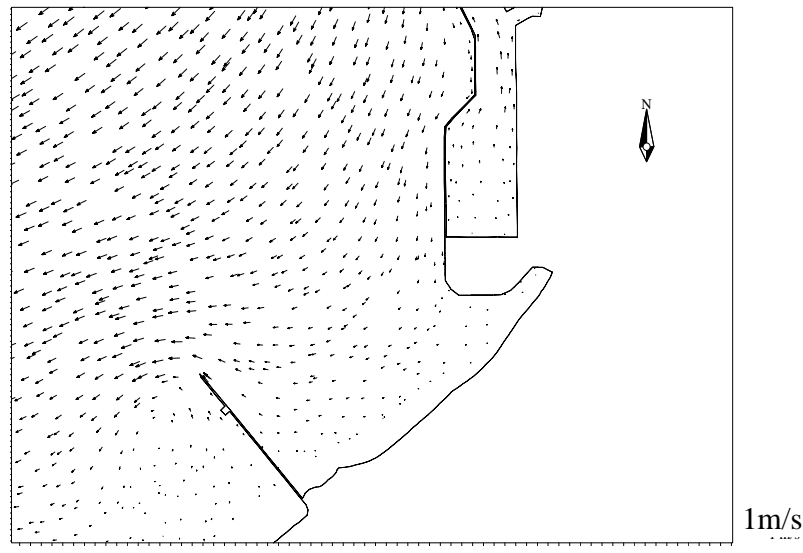

Figure 1Flow field pattern before project at high tide intermediate time

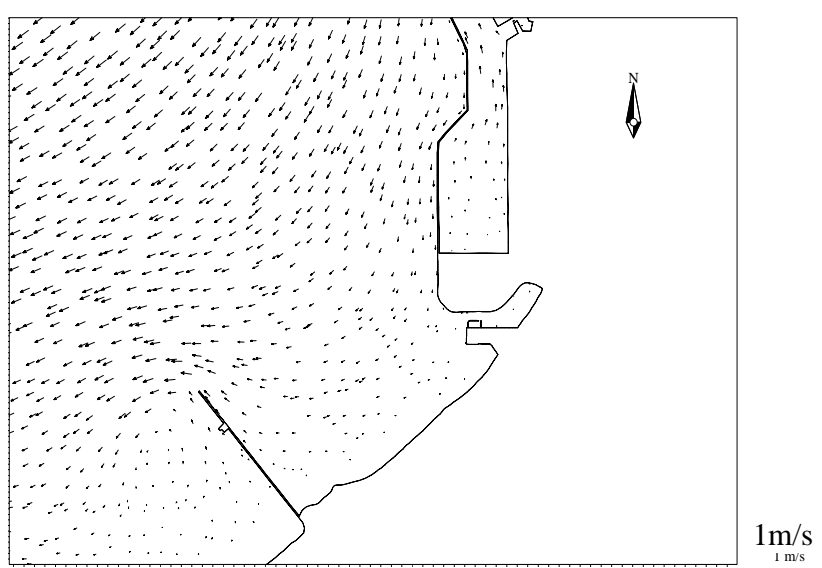

Figure 2 Flow field pattern after project at high tide intermediate time 


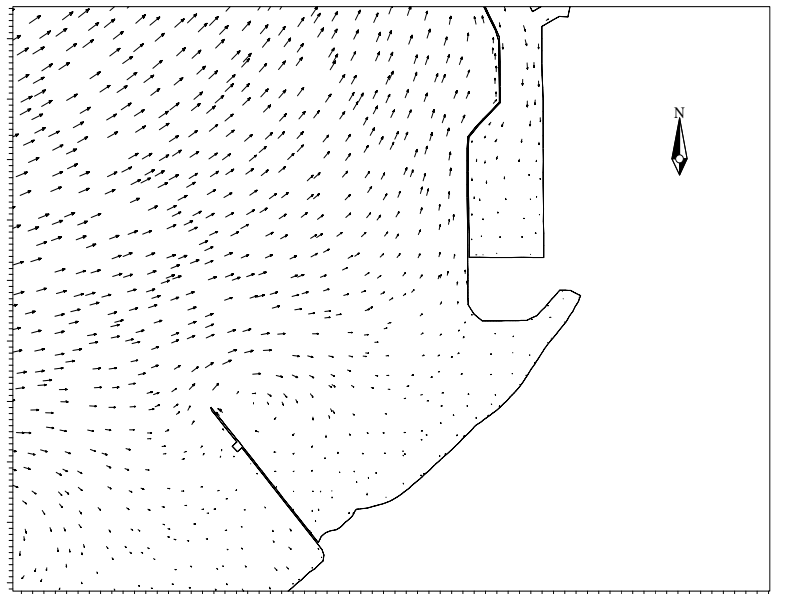

Figure3Flow field pattern before project at ebb tide intermediate time

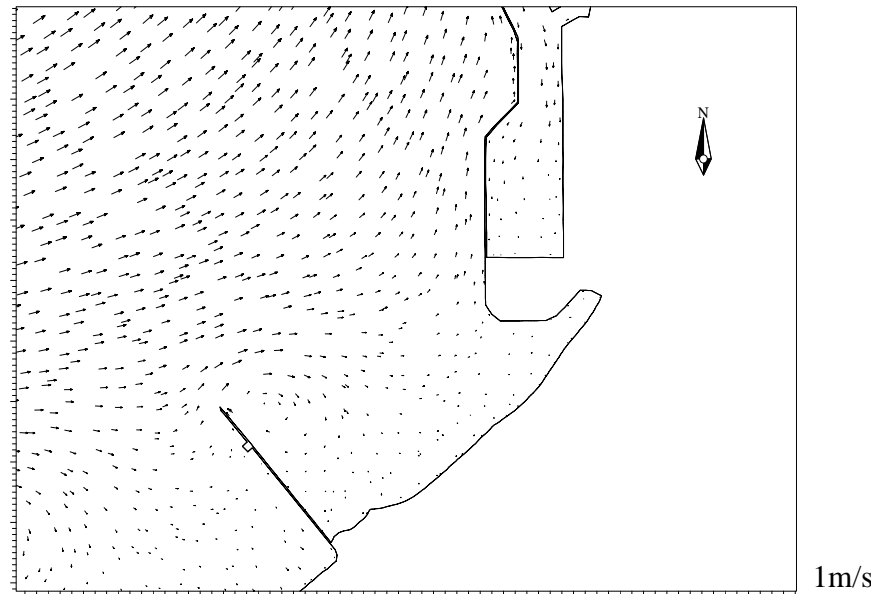

Figure 4 Flow field pattern after project at ebb tide intermediate time

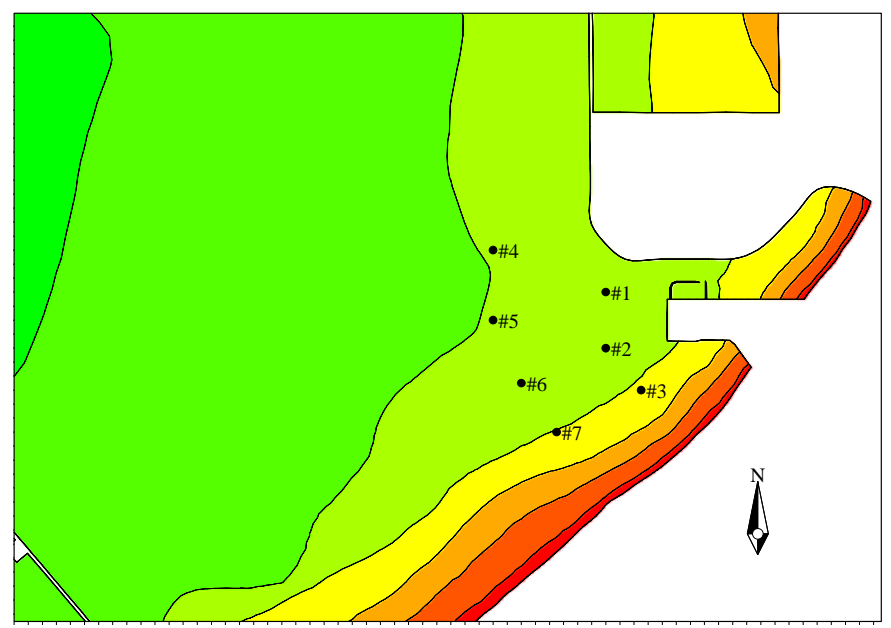

Figure 5 Relative position of the representative point

\section{Prediction and analysis of suspended sediment concentration field}

During the construction process, coarse seabed sediment settling quickly, fine sediment particles suspended in the water for a long time and with the transport and diffusion currents, suspended sediment form field. Calculations consider only increase reclamation projects suspended sediment transport, regardless of background concentrations.

Sediment transport and diffusion model, using two-dimensional consider settlement of suspended solids transport and diffusion equation.

$$
\frac{\partial P}{\partial t}+U \frac{\partial P}{\partial y}+V \frac{\partial P}{\partial y}=\frac{\partial}{\partial x}\left(D_{x} \frac{\partial P}{\partial x}\right)+\frac{\partial}{\partial y}\left(D_{y} \frac{\partial P}{\partial y}\right)+S_{d}+S_{s}
$$

Dx, Dy are the horizontal eddy diffusion coefficient on the $\mathrm{x}$ and $\mathrm{y}$ directions, using empirical formulas. $\mathrm{K}$ is empirical coefficient, here is $0.05 ; \Delta X_{i}$ is respectively $\mathrm{x}$, $\mathrm{y}$ direction grid scale; speed respectively $\mathrm{x}, \mathrm{y}$ direction. Sd is the settlement terms, Ss is the source of strength.

Simulation calculations only consider the impact on the trend of sediment transport and diffusion. From a tidal cycle process it can be seen: at high tide, with the rising tide, suspended sediment diffuse to the east and southeast; at low tide, with the ebb current, suspended sediment diffuse to the west and southwest. Since the sea around the source strength is small, the high concentration of suspended sediment is limited to engineering construction range , maximum concentration is $331 \mathrm{mg} / \mathrm{l}$. Figure 8 is the largest scope of suspended sediment envelope foundation trench excavation and dredging basin 
during the period. Less impact on the adjacent waters of suspended sediment, such as concentrations of $100 \mathrm{mg} / \mathrm{l}$ line influence the farthest distance is $450 \mathrm{~m}$, concentrations of $50 \mathrm{mg} / \mathrm{l}$ line influence the farthest distance is $1200 \mathrm{~m}$, concentrations of $10 \mathrm{mg} / \mathrm{l}$ line influence the farthest distance is $2900 \mathrm{~m}$. 12 hours after the end of construction, the maximum concentration of suspended sediment is $45 \mathrm{mg} / \mathrm{l}$. Construction of the marine environment will be some impact, but this effect is temporary, after the construction, suspended sediment concentrations in the sedimentation gradually reduced, pollution will disappear.

\section{Summary}

We can draw the following conclusion:

After the completion of the project, changes to the tidal current field are mainly concentrated on the area near engineering sea. As the sea is at high tide, the representative point velocity of engineering area increases, single range is smaller and the change of flow direction is very small; while as the sea is at low tide, the most representative point velocity of engineering area turns to small, the change of flow direction is very small and the influence of engineering construction on the ebb current is more apparent than flood. However, the flow velocity of engineering waters is no more than $10 \mathrm{~cm} / \mathrm{s}$ which is very small. The influence of engineering on tidal current field of waters beyond 1000 meters away from the selected area is a little small.

Based on the suspended sediment concentration field changing with current during construction period, we can draw the following conclusions: due to the intensity of sources of enclosing sea is small, high concentration of suspended sediment which is caused by the engineering is limited to scope of construction and the highest concentration can achieve to $331 \mathrm{mg} / \mathrm{l}$. Suspended sediment has less effect on the surrounding waters, the longest distance of the influence on the isopleth of $100 \mathrm{mg} / \mathrm{l}$ is $450 \mathrm{~m}$, while the distance is $1200 \mathrm{~m}$ and $2900 \mathrm{~m}$ respectively when related to the isopleth of $50 \mathrm{mg} / \mathrm{l}$ and $10 \mathrm{mg} / \mathrm{l}$. The construction period will cause certain influence on the waters environment; however, the effect is temporary. Under the effect of sedimentation, the concentration of suspended sediment will decrease gradually and pollution effect will disappear after the completion of construction.

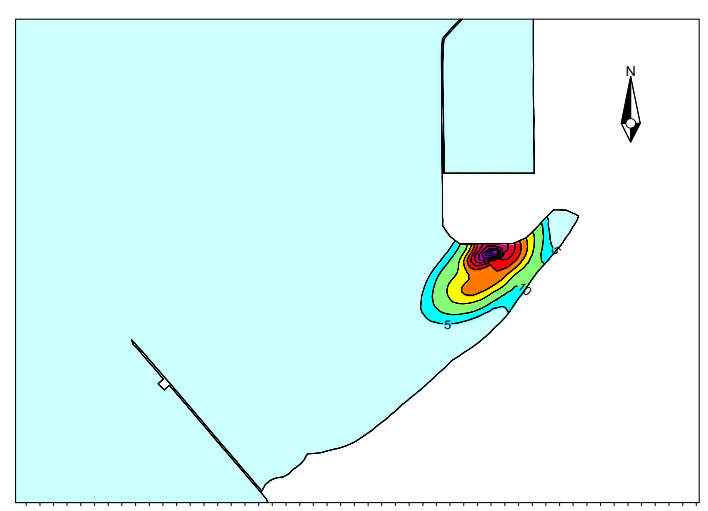

Figure6Initial distribution of suspended sediment concentration field
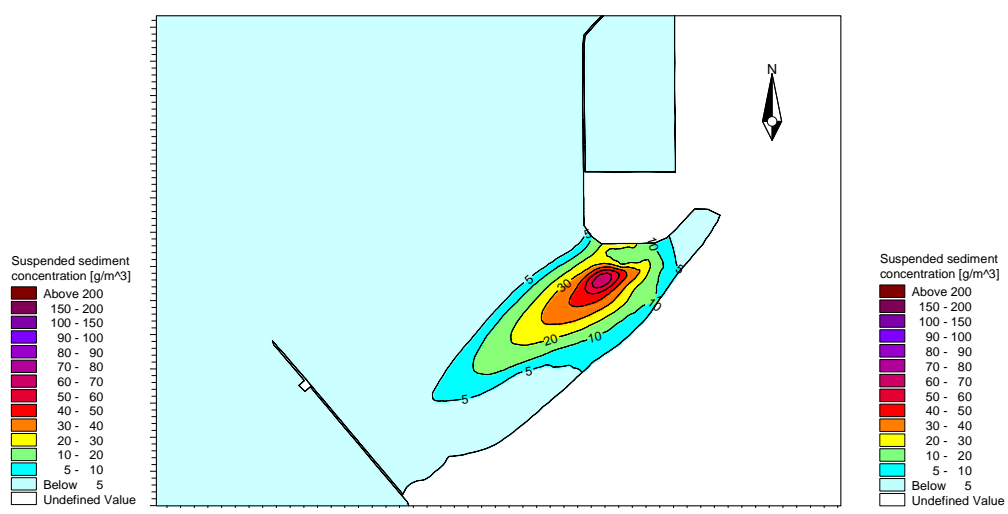

Figure7 Late distribution of suspended sedimen concentration field

\section{Acknowledgements}

Thanks for the support of the National Natural Science Foundation of China (No.31302232). 


\section{References}

[1] Lin Bingnan, Huang Juqing ,Li Xinchun, Mathematical Model of Suspended Transport by Tidal Flow in the Qiantang Estuary[J].Journal of Sediment Research, 1981,(2).16-29.

[2] Wang Guang qian, Zhou Jianjun, 2-D Numerical Model of Sediment-density Current [J] Journal of basic science and engineering, 2000.8(1):52-60

[3] Van Rijn, L.C., 1987. Mathematical modeling of morphological processes in the case of suspended sediment transport. Delft Hydraulics Communication No.382:P127.

[4] Van Rijn, L.C., 1990. FieId verification of 2-D and 3-D suspended sediment models, Journal of Hydraulic Engineering, ASCE, 116(10): 1270-128 